\title{
Does market access mitigate the impact of seasonality on child growth? Panel data evidence from North Ethiopia
}

\author{
Kibrewossen Abay ${ }^{\text {a }}$ \\ Kalle Hirvonen ${ }^{\text {a }}$ \\ ${ }^{a}$ International Food Policy Research Institute, Addis Ababa, Ethiopia
}

This version: 31 January 2016

\begin{abstract}
Using high-frequency panel data from North Ethiopia, this study analyzes the role of seasonality on children's growth patterns. In line with earlier studies, we document considerable seasonality in children's (age and height adjusted) weights. Children located closer to food markets are better nourished compared to their counterparts residing in more remote areas. However, children's weights are subject to considerable seasonal fluctuations irrespective of their households' proximity to local food markets. While market access is not sufficient to insulate children from seasonal weight fluctuations, we do find evidence that children located closer to the markets consume more diverse diets than those located farther away. However, the protein content of this diet varies across the seasons. These findings remind us that seasonality remains largely an unsolved problem that continues to contribute to child under-nutrition in low income countries.
\end{abstract}

Keywords: child anthropometrics, dietary diversity, food markets, Africa

JEL codes: I15, O12, Q18, O13

Acknowledgements: Funding for this work was received through the Feed-the-Future project funded by the United States Agency for International Development. The survey was funded by UNICEF. We thank Thomas Woldu Assefa for useful comments and Helina Tilahun for the help with the GIS data. 


\section{Introduction}

Child under-nutrition remains a major problem in low income countries. In Sub-Saharan Africa alone 56.9 million children (40 percent) are stunted and 31.1 million are underweight (22 percent) (Black et al. 2013). While a tragedy in its own right, under-nutrition leads to enormous economic losses, for example, through reduced human capital (Behrman, Alderman, and Hoddinott 2004). Under-nourished children tend to score poorly in cognitive tests and also attain less education (Glewwe, Jacoby, and King 2001, Alderman, Hoddinott, and Kinsey 2006, Mendez and Adair 1999), and thus become less productive adults. Horton and Steckel (2013) estimate that each year, sub-Saharan Africa loses 11 percent of its Gross National Product due to poor nutrition.

Seasonal energy stress is considered a major contributor to under-nutrition in sub-Saharan Africa and other low income settings (Ferro-Luzzi and Branca 1993, Vaitla, Devereux, and Swan 2009). Most farmers in sub-Saharan Africa rely on rain-fed agriculture (Faurès and Santini 2008), resulting in considerable seasonal fluctuations in local food availability and prices (Hirvonen, Taffesse, and Worku 2015, Kaminski, Christiaensen, and Gilbert 2014, Gilbert, Christiaensen, and Kaminski 2015). Moreover, a large body of literature documents how children's and adult's anthropometric outcomes fluctuate across agricultural seasons (Ferro-Luzzi et al. 2001, Maleta et al. 2003, Alemu and Lindtjørn 1995, Leonard 1991, Panter-Brick 1997, Dercon and Krishnan 2000), thus confirming the link between seasonal energy stress and under-nutrition. Low energy intakes, even temporary ones, can have serious nutritional implications, especially for young children.

This paper contributes to this vast - though recently somewhat neglected (Devereux, Sabates-Wheeler, and Longhurst 2012) - literature on seasonality by studying how market access interacts with the impact of seasonality on child growth. Previous literature highlights the role of market and road access on household welfare and food consumption patterns. Handa and Mlay (2006) find how Mozambican households with access to roads, are better equipped to smooth their consumption across the agricultural seasons. This could be because households with road access are more likely to engage in non-farm activities (Jacoby and Minten 2009) which could provide them with additional income during the lean season. Less remote farmers are also able to get better prices for their produce in the post-harvest period and are less exposed to seasonal variation in food prices (Minten 1999). Moreover, emerging research evidence from Ethiopia suggests that households located closer to markets enjoy better diets (Stifel and Minten 2015), and their food consumption is less dependent on their own agricultural production 
(Hirvonen and Hoddinott 2014, Hoddinott, Headey, and Dereje 2015). Therefore, the hypothesis that households which have greater access to markets are able to protect their children better seems plausible - but so far (to our knowledge) untested. ${ }^{1}$

In this paper, we attempt to test this hypothesis using high-frequency panel data from eight villages in North Ethiopia. The survey collected anthropometric measures of children approximately in threemonthly intervals between 2012 and 2014 resulting in panel data spanning seven rounds. Categorizing the interview dates into lean and food sufficient seasons (i.e. non-lean), we first show how children's weights are subject to considerable seasonal fluctuations. As expected, age or height adjusted weight measures are lower in the lean season verifying the earlier findings from Ethiopia and other low income settings. We then study whether market access mitigates the impact of seasonality on child growth patterns. We find that children residing in households with better access to local food markets have higher Z-scores for Weight-for-Height and Weight-for-Age. However, while these children are better nourished than the children located farther away from food markets, their (height or age adjusted) weights are also subject to considerable seasonal fluctuations. The seasonal changes in the Z-scores are of similar magnitude to the ones observed in the more remote areas.

Households with better market access are therefore also unable to protect their children from seasonality. This could be because food prices in these markets are subject to considerable seasonality. A recent study by Gilbert, Christiaensen, and Kaminski (2015) provides support to this hypothesis. The authors document considerable seasonal price gaps - the difference in prices just before and after the harvest - in Ethiopia and 10 other African countries. ${ }^{2}$ This implies that the local food markets are not well integrated, thus mainly sourcing food products from nearby localities. As a result, food prices in these markets closely follow the local food production patterns. High food prices together with low incomes and diminished

\footnotetext{
${ }^{1}$ Recent study by Darrouzet-Nardi and Masters (2015) focused on the impact of season of birth on HAZ scores measured later in life. Using two rounds of DHS data for the Democratic Republic of Congo, the authors find that children born in the lean season have systematically lower HAZ scores than other children and that being located farther away from towns and cities exacerbates this adverse seasonality effect. The focus in the current paper is different. Using high-frequency panel data over a two-year period, we study how seasonality affects children's growth patterns (after their birth) and whether closer proximity to markets mitigates these effects.

${ }^{2}$ For Ethiopia, Gilbert el al use monthly price data for 2003-2012 from 11 wholesale markets. As expected, the prices of perishable food items displayed highest seasonality. For example, the estimated seasonal price gap in Ethiopia for oranges was 21 percent and for tomatoes more than 35 percent. However, considerable seasonal price gaps were also found for cereals: for maize the seasonal price gap was estimated to be 20 percent, for teff 10 percent and for sorghum nearly 14 percent.
} 
food stocks then lead households to cut back on their food consumption and change the content of their diets (Hirvonen, Taffesse, and Worku 2015).

This paper speaks to the fast evolving research literature which focuses on linkages between agriculture and nutrition (Carletto et al. 2015, Herforth, Jones, and Pinstrup-Andersen 2012). However, so far there has been little evidence that agricultural interventions lead to improvements nutritional outcomes (Ruel and Alderman 2013, Masset et al. 2012, Berti, Krasevec, and FitzGerald 2004). One reason could be the limited attention to seasonality in this research program and the strong focus on improving agricultural outcomes during the main agricultural season. Yet, based on the findings in this paper, seasonality remains a major issue for children's health in low income settings. Recent evidence from Tanzania suggests that early childhood exposure to consumption seasonality may even shape adult outcomes (Christian and Dillon 2015).

\section{Context, data and descriptive analysis}

This study focuses on Tigray, the northernmost region of Ethiopia. The undernutrition rates in this region are among the highest in the country: 51 percent of children are stunted, 35 percent are underweight and 10 percent are wasted (Central Statistical Agency and ICF International 2012). Bordering Sudan in the west and Eritrea in the north, the 2007 census reported a population of 4.3 million. Tigray is overwhelmingly rural and the mountainous terrain makes travelling difficult and time-consuming.

The data used in this paper come from a household panel survey from South-Eastern part of Tigray implemented between May 2012 and July 2014. These data were collected by the International Food Policy Research Institute (IFPRI), the Institute of Development Studies and the Department of Economics in Mekelle University. The purpose of the survey was to assess the impact of the Social Cash Transfer Pilot Program (SCTPP) organized by the Regional Government of Tigray, together with the United Nations Children's Fund (UNICEF). The goal of the SCTPP project was to improve the quality of life for vulnerable children, the elderly, and persons with disabilities.

The 'treatment' sample was drawn from a list of beneficiary households. This list consisted of four different household types: the elderly, the disabled, child-headed households ${ }^{3}$, and female-headed households. To ensure that a sufficient number of children were in the final sample, the evaluation team

\footnotetext{
${ }^{3}$ This refers to households where the head is less than 18 years of age.
} 
decided to oversample non-elderly households. The final sample consists of three sub-samples: 1) a treatment sample: households that received SCTPP benefits; 2) a control sample: households that met the target criteria but did not receive the SCTPP benefits; and 3) a random sample: households that did not meet the target criteria and did not receive SCTPP benefits.

In this paper, we ignore this experimental design in the sampling and instead use these rich data to study the role of seasonality on child nutrition outcomes. The original impact evaluation, reported in Berhane et al. (2015), found that while the project improved household diets (calories and dietary diversity), it had no statistically significant impact on household (self-reported) food security or young children's nutritional status (stunting, HAZ, wasting or WHZ). ${ }^{4}$

The survey was fielded in the two districts (woredas) in East-Tigray where the SCTPP pilot took place; in Abi Adi, an urban district north of the regional capital Mekelle and Hintalo Wajirat, a rural district south of Mekelle. We restrict the analysis to the rural district, Hintalo Wajirat where 2,387 households from eight tabias (sub-districts in local language) and 27 kushets (villages in local language) were selected for the final sample. 5 The motivation for this restriction is due to the fact that these eight surveyed tabias are all rural and located close to each other, thereby sharing the same climate and weather. Moreover, virtually all households engage in agricultural production, whereas the opposite is true for the households in the urban sample. ${ }^{6}$ The terrain in Hintalo Wajirat is rugged with altitudes ranging between 2,000 and 2,600 meters. Figure 2.1 shows where the kushets (marked with black dots) are located in the district. Households in this district rely on four food markets (marked with stars). The (Euclidian) distance to the nearest food market varies across the kushets, ranging from minimum of 0.5 kilometers to maximum of 9 kilometers. ${ }^{7}$ About one fourth of the kushets are located within a $3.5 \mathrm{~km}$ distance from a food market.

We use these rich panel data to study seasonality in child health outcomes. With 7 rounds of data collected over a 24-month period, this survey is ideal for such an analysis. Regarding attrition, 90.5 percent of households interviewed at the baseline survey were interviewed at the end-line. This 9.5 percent attrition

\footnotetext{
${ }^{4}$ For more information about the survey and the impact evaluation, see Berhane et al. (2015).

5 1,280 households were interviewed in Abi Adi woreda.

${ }^{6}$ As a result, their production is less affected by seasonality in rainfall patterns.

${ }^{7}$ The Euclidian distances are based on GPS coordinates that were recorded for each household and each food market. We calculated the distance to the nearest market and then took the median distance for each kushet to minimize the role of measurement error. However, the results are robust to using distances defined at the household level as well (results available upon request).
} 
was concentrated in two tabias where some respondents declined to participate again in the survey citing religious reasons (Berhane et al. 2015). We explored the correlates of this attrition using a probit model and found that it is not correlated with any of the child or household level characteristics, including WHZ and WAZ and household wealth. The results from the probit model analysis are not reported in this paper, but are available upon request.

As in other parts of Ethiopia, farming in Hintalo Wajirat is based on rain-fed agriculture, and therefore agricultural production takes place in seasonal cycles. Figure 2.2 shows the average rainfall patterns in the area. Farmers rely mainly on the long rainy season (meher) that takes place between June and October. ${ }^{8}$ This is followed by the harvest period, typically occurring between October and November (Hirvonen, Taffesse, and Worku 2015). After the harvest, households depend largely on their stored food stocks. Figure 2.3 shows how consumption from own production is high at 90 percent immediately after the harvests and declines to 30 percent during the lean season months. The two figures highlight the extent of seasonality in agricultural production and consumption in this context. Using this information, we categorized the calendar year - and our survey rounds - into lean season months and into food sufficient months. The lean season months occur between May and September whereas the food sufficient months occur between October and April. Table 2.1 shows the survey dates. The survey occurred during three lean seasons and four food sufficient months.

The survey collected measurements of the height and weight of each child less than five years old in each survey round. We focus on weight based measures, weight-for-height (WHZ) and weight-for-age (WAZ) Z-scores, ${ }^{9}$ that capture the current or recent nutritional status of children, and are therefore considered more responsive to seasonal changes than the often used height based indicators, i.e. height-for-age Zscore (Khara and Dolan 2014). More than half of the children included in these data are stunted ${ }^{10}, 27$ percent are underweight ${ }^{11}$ and 8 percent are wasted ${ }^{12}$ (Table 2.2). Therefore, despite the nonrepresentative sampling, the under-nutrition rates in this sample are similar to those rates reported for the

\footnotetext{
${ }^{8}$ The rains during the short rainy season (belg) are small in magnitude and not reliable and therefore only little cultivation takes place during this period.

${ }^{9}$ The Z-scores measure the distance to the median weight of a healthy and well-nourished reference population of same sex and age/height. This distance is measured in terms of standard deviations of that same reference population. We used the WHO (2006) as the reference population and computed the z-scores using zanthro06 command (Leroy 2011) in Stata 14. Z-score observations that were below -5 or above +5 standard deviations were considered outliers and dropped from the analysis.

${ }^{10}$ A child is categorized stunted if his or her height-for-age is below -2 standard deviations.

${ }^{11}$ A child is categorized underweight if his or her weight-for-age is below -2 standard deviations.

${ }^{12}$ A child is categorized wasted if his or her weight-for-height is below -2 standard deviations.
} 
region (see above). Moreover, Figures 2.4 and 2.5 show that the growth faltering in weight-for-height and weight-for-age follows the typical pattern observed in many other low income countries (Victora et al. 2010).

\section{Methods}

We model the anthropometric outcome $\left(y_{i v t}\right)$, WAZ or WHZ, for child $\mathrm{i}$ at time $\mathrm{t}$ residing in village $\mathrm{v}$ as a function of the season when the child was measured:

$$
y_{i v t}=\beta_{1} s_{i v t}+\beta_{2} d_{v t}+\beta_{3}\left(s_{i v t} * d_{v t}\right)+c_{i v t}{ }^{\prime} \gamma+x_{i v t}{ }^{\prime} \delta+t_{t}+\varepsilon_{i v t},
$$

where $s_{i v t}$ captures the season in which the child was measured; equal to one if the interview took place in the lean season, and zero otherwise. Variable $d_{v t}$ measures the distance to the nearest food market. We also include an interaction term of these two variables $\left(s_{i v t} * d_{v t}\right)$ to see whether the seasonal fluctuations differ across the distance to the nearest food market. The term $x_{i v t}^{\prime}$ is a vector of household level characteristics including characteristics of the head of household (age, sex, literacy), and household wealth (productive and non-productive assets) and demographics (number of household members in different age groups by sex). Child specific controls $c_{i v t}{ }^{\prime}$ include sex and age in months (spline function: knots at 6, 12 and 24 months). Table 2.2 provides the summary statistics for all variables used in the analysis. Finally, the term $t_{t}$ is the linear time trend to capture general, non-seasonal, trends in children's anthropometric outcomes over the 24 month period and $\varepsilon_{i v t}$ is the error term. The standard errors are clustered at the kushet level.

It may be that the distance to markets has a non-linear relationship between children's weights. To account for this possibility, we also estimate the following model:

$$
y_{i v t}=\beta_{1} S M_{i v t}+\beta_{2} S N M_{i v t}+\beta_{3} L M_{i v t}+c_{i v t}{ }^{\prime} \gamma+x_{i v t}{ }^{\prime} \delta+t_{t}+\varepsilon_{i v t} .
$$

where $S M_{i v t}$ equals one if the season is food sufficient (i.e. non-lean) and village is located close to a food market (within $3.5 \mathrm{~km}$ distance) ${ }^{13}$ and zero otherwise, $S N M_{i v t}$ equals one if the season is food sufficient and the village is not located close to a food market and $L M_{i v t}$ equals one if the season is lean and the

\footnotetext{
${ }^{13}$ Our results are robust to using different cut-off points (e.g. 3, 4.5, 5 and $5.5 \mathrm{~km}$ ). Results are available upon request.
} 
village is located close to a food market. The $\beta$ coefficients then capture the effect of seasonality for each village type relative to the reference group: lean season and the village is located far from a market. We therefore expect that each $\beta>0$.

\section{Results}

Table 4.1 shows the regression results based on Equation 1. The odd columns use WHZ as the dependent variable and the even columns are based on WAZ. In the first two columns the interaction term is omitted and the last two columns estimate the full model. We see that seasonality exerts considerable fluctuations on children's weights: during the lean season the weight-for-height Z-scores are, on average, -0.29 units of standard deviation lower than during the food sufficient season, after controlling for age effects, household wealth and demographics. The lean season exerts a similar impact on weight-for-age Z-scores: -0.20 unit of standard deviation drop in the WAZ scores. For the average child in our data of 34 months of age, one standard deviation in WAZ translates into 1.7 kilograms. Therefore, the average child in our sample is 0.34 kilograms $(0.2 \times 1.7 \mathrm{~kg})$ lighter during the lean season relative to the food sufficient season. Furthermore, children who are located farther away from a food market have lower WHZ and WAZ scores. In columns 3 and 4 we interact the distance variable with the lean season dummy thereby estimating the full model presented in Equation 1. The coefficient on this variable will tell us whether the impact of seasonality differs across the market gradient. The coefficient on the interaction term appears insignificant in both columns implying that the seasonal fluctuations do not differ between the more or less remote households.

We also estimated Equation 1 using village fixed effects. The distance to market is measured at the village level, and therefore we had to omit this variable from the model. The results are presented in Table 4.2. First, the coefficients in column 1 and 2 are very similar to the corresponding coefficients presents in Table 4.1. This implies that the previous results are not driven by some unobserved time-invariant village characteristics. The coefficients on the interaction terms are also of similar magnitude but the estimated standard errors are somewhat smaller. As a result, the coefficient on the WHZ model appears with a marginally statistically significant (and negative) coefficient. This suggests that the lean season impact on children's WHZ increases as we move away from the food markets. However, the coefficient is statistically significant only at the 10 percent level. Moreover, we estimated Equation 1 also using household fixed effects. The results were very similar to those obtained in Tables 4.1 and 4.2 and therefore not presented here. 
Table 4.3 presents the regression results based on Equation 2. First, we see that WHZ scores are, on average, 0.18 units and WAZ scores 0.19 units higher during the lean season in the kushets closer to a food market (relative to more remote kushets). Second, during the non-lean season WAZ scores are 0.31 units higher in kushets with good market access compared to the kushets with poorer market access $(0.484$ $0.177=0.31, \mathrm{p}=0.022$ ). For the average child in our sample, this $0.31 \mathrm{WAZ}$ units translates into 0.53 kilograms. For WHZ this difference is not statistically significant $(\mathrm{p}=0.58)$. Finally, children's weights fluctuate considerably across the two seasons both in villages with good market access and in villages with poorer market access. In villages closer to the market, WHZ is $0.198(=0.383-0.185, p=0.005)$ and WAZ $0.292(=0.484-0.192, \mathrm{p}<0.001)$ units higher in non-lean season than in the lean season. Similarly, in villages farther away, WHZ is $0.312(\mathrm{p}<0.01)$ and WAZ $0.177(\mathrm{p}<0.01)$ units higher in non-lean season. To summarize these findings, we find that while children located near the food markets are better nourished, their (height and age) adjusted weights are subject to seasonality that is of similar magnitude of as the children located farther away from the markets.

\section{Exploring potential pathways}

The regression results presented in the previous section show two things. First, children's weights are subject to considerable seasonality - irrespective of their proximity to the food markets. Second, despite this, children located closer to the food market are have higher age and height adjusted weights than children living the more remote areas. In this section, we attempt to further understand these two findings. The two most important immediate causes of child malnutrition are inadequate diets and illnesses (UNICEF 1998). In this penultimate section we study how seasonality and market access affect children's diets and the risk of contracting an illness (diarrhea).

Unfortunately, we do not have information about the quantities of children's food consumption. However, the survey comprised a series of Yes/No questions about children's consumption of 15 different food items in the last 7 days. ${ }^{14}$ We used these data to construct a household level index ranging in value from zero to $15 .^{15}$ The mean weekly dietary diversity in our sample is 3.9 food groups (standard deviation: 2.44), confirming observations from earlier studies that Ethiopian children follow extremely monotonous diets

\footnotetext{
${ }^{14}$ These food items are: Injera; Other foods made with grains; Roots and tubers; Orange colored vegetables; Leafy dark green vegetables; Other vegetables; Fruit; Meat; Eggs; Fresh, canned or dried fish or other seafood; Legumes; Dairy product; Fats and oils; Sugar, honey, sweets; Coffee, tea, soft drinks.

15 This type of simple dietary diversity index has been shown to be correlated with children's anthropometric measures in different context (Arimond and Ruel 2004, Jones et al. 2014), including Ethiopia (Disha et al. 2012).
} 
(Headey 2014, Hirvonen and Hoddinott 2014). We then regressed this household level dietary diversity indicator on our seasonality and market access variables, together with the controls used in the previous regressions.

Column 1 in Table 5.1 provides the results. First, we see that children located in villages with better market access enjoy more diverse diets during the good season ( 0.375 food groups; $0.710-0.335, \mathrm{p}=0.025$ ) and also during the lean season ( 0.71 food groups, $\mathrm{p}<0.01$ ), relative to the children residing farther away from the food markets. We also assessed whether the likelihood of consuming animal source foods (ASF) and more specifically dairy products changes across the seasons and across the market access dimension. ${ }^{16}$ Previous research from Ethiopia shows how children's dairy consumption has been associated with better anthropometric outcomes (Hoddinott, Headey, and Dereje 2015). We find that children located closer to the markets are more likely to consume ASF but only during the good season (Column 2). This seems to be driven by dairy product (mostly milk) consumption (Column 3). Columns 1 to 3 then suggest that the children who are located closer to the markets consume more diverse diets with no changes across the two seasons. However, the content of this diet changes: the consumption of dairy products - that rich in protein - increases considerably in the good season.

Finally, an alternative pathway in which seasonality can affect children's weight is through an increased illness risk during the lean season. Indeed, earlier findings from South Ethiopia suggest that the seasonal weight losses were driven by diarrhea episodes rather than changes in food availability (Ferro-Luzzi et al. 2001). ${ }^{17}$ To assess this, we use the data on children's diarrhea episodes 4 weeks prior the interview. ${ }^{18}$ Nearly 10 percent of the children in our sample reported diarrhea in this period. In column 4 in Table 5.1 we regress this binary variable on the seasonality and market access variables (and the controls). Overall, we find little evidence that the trends in WHZ and WAZ scores observed in the previous section are driven by diarrhea outbreaks. In contrast, and somewhat puzzlingly, we find suggestive evidence that the probability of a child contracting diarrhea is somewhat higher in the good season in the more remote kushets. However, this estimate is statistically significant only at the 10 percent level.

\footnotetext{
${ }^{16}$ In the pooled sample, 26.0 percent of the children consumed animal source foods and 11.9 percent consumed dairy products in the past 7 days.

${ }^{17}$ Of note is that the southern part of the country has a bi-modal rain pattern so the seasonal availability of foods is less of an issue compared to North Ethiopia.

${ }^{18}$ Note that there is no (seasonal) malaria risk in this area due to the high altitude.
} 


\section{Conclusions}

In this paper we have documented how children located closer to the markets are healthier and better nourished compared to their counterparts residing in the more remote areas. However, we also find that children's (age or height adjusted) weights are subject to considerable seasonal fluctuations - irrespective of their households' market access. Further analysis on children's diets reveal that children located closer to the markets consume more diverse diets throughout the year. However, the content of this diets vary: children near markets are much more likely to consume milk or milk products during the good season than in the lean season.

This leads us to conclude that while proximity to food markets facilitates access to more diverse diets, households located closer to these markets are not able to insulate children from seasonal weight fluctuations. One possible explanation for this latter finding is that food prices in these markets are subject to considerable seasonality as documented in Gilbert, Christiaensen, and Kaminski (2015). This points to three policy options. First, investments in better storage technologies could go a long way in decreasing seasonal price volatility but mainly among the less perishable staple crops. Second, expanding irrigation would allow food to be produced outside the main cropping season thereby shortening the lean season period and reducing the seasonal energy stress among households (Headey et al. 2015). The third policy option is to improve market integration. The considerable seasonality in food prices implies that the food markets in Ethiopia are not integrated with the other regions, thus mainly sourcing food products from nearby areas. The geography of Ethiopia, however, offers great potential for improving seasonal food availability through cross-regional trade. The country is large covering more than one million square kilometers and comprising a number of different agro-ecological zones in which food is being produced. Moreover, the seasonal weather patterns vary across the country with some areas relying on two agricultural seasons instead of one. Furthermore, a better market integration would allow producers to maximize their incomes through specialization while ensuring that households have access to nutritious foods (through properly integrated food markets). Effective behavioral change communication would then

play an important role to ensure that the demand for a diverse range of food types remains high so that producers have the incentive to produce such foods.

Finally, this study has limitations. First, we do not have information about the food quantities consumed by the children. The analysis of dietary diversity suggest that children located to closer to food markets enjoy more diverse diets than children located in more remote areas. However, the consumption of animal 
source foods and especially dairy products declines dramatically during the lean season in the areas that are closer to the market. This could then explain some of the seasonal weight fluctuations among children located closer to the markets. Nevertheless, it is likely that households also cut back on consumed quantities during the lean season (see Hirvonen, Taffesse, and Worku 2015). Unfortunately due to lack of data we cannot verify this hypothesis. Finally, the analysis focused only on one district (woreda) in the Tigray region thereby limiting the external validity of this study. 


\section{References}

Alderman, Harold, J. Hoddinott, and B. Kinsey. 2006. "Long term consequences of early childhood malnutrition." Oxford Economic Papers-New Series 58 (3):450-474.

Alemu, Tadesse, and Bernt Lindtjørn. 1995. "Physical activity, illness and nutritional status among adults in a rural Ethiopian community." International journal of Epidemiology 24 (5):977-983.

Arimond, Mary, and Marie T Ruel. 2004. "Dietary diversity is associated with child nutritional status: evidence from 11 demographic and health surveys." The Journal of Nutrition 134 (10):2579-2585.

Behrman, Jere R, Harold Alderman, and John Hoddinott. 2004. Hunger and malnutrition. In Copenhagen Consensus - Challenges and Opportunities.

Berhane, Guush, Stephen Devereux, John Hoddinott, Jessica Hoel, Keetie Roelen, Kibrewossen Abay, Martha Kimmel, Natasha Ledlie, and Thomas Woldu. 2015. Evaluation of the Social Cash Transfers Pilot Programme, Tigray Region, Ethiopia, Endline Report. Washington, DC, International Food Policy Research Institute.

Berti, Peter R, Julia Krasevec, and Sian FitzGerald. 2004. "A review of the effectiveness of agriculture interventions in improving nutrition outcomes." Public health nutrition 7 (05):599-609.

Black, Robert E, Cesar G Victora, Susan P Walker, Zulfiqar A Bhutta, Parul Christian, Mercedes De Onis, Majid Ezzati, Sally Grantham-McGregor, Joanne Katz, and Reynaldo Martorell. 2013. "Maternal and child undernutrition and overweight in low-income and middle-income countries." The Lancet 382 (9890):427451.

Carletto, Gero, Marie Ruel, Paul Winters, and Alberto Zezza. 2015. "Farm-Level Pathways to Improved Nutritional Status: Introduction to the Special Issue." The Journal of Development Studies.

Central Statistical Agency, and ICF International. 2012. Ethiopia Demographic and Health Survey 2011. Addis Ababa, Ethiopia and Calverton, Maryland, USA: Central Statistical Agency and ICF International.

Christian, Paul, and Brian Dillon. 2015. Long-Term Consequences of Consumption Seasonality. Paper presented at the Structural Transformation of African Agriculture and Rural Spaces (STAARS) conference in Addis Ababa, December 2015.

Darrouzet-Nardi, Amelia, and William Masters. 2015. "Does Market Access Protect Children against Poor Health Conditions at Birth?" The FASEB Journal 29 (1 Supplement):898.22.

Dercon, Stefan, and Pramila Krishnan. 2000. "In sickness and in health: Risk sharing within households in rural Ethiopia." Journal of Political Economy 108 (4):688-727.

Devereux, Stephen, Rachel Sabates-Wheeler, and Richard Longhurst. 2012. Seasonality, rural livelihoods and development. London and New York: Routledge.

Disha, AD, R Rawat, A Subandoro, and P Menon. 2012. "Infant and Young Child Feeding (IYCF) practices in Ethiopia and Zambia and their association with child nutrition: analysis of Demographic and Health Survey data." African Journal of Food, Agriculture, Nutrition and Development 12 (2):5895-5914. 
Faurès, Jean-Marc, and Guido Santini. 2008. Water and the rural poor: interventions for improving livelihoods in sub-Saharan Africa. Rome, Italy: Food and Agriculture Organization (FAO).

Ferro-Luzzi, Anna, and Francesco Branca. 1993. "Nutritional seasonality: the dimensions of the problem." In Seasonality and human ecology, edited by S. J. Ulijaszek and S. S. Strickland. New York: Cambridge University Press.

Ferro-Luzzi, Anna, Saul S Morris, Samson Taffesse, Tsegaye Demissie, and Maurizio D'Amato. 2001. Seasonal Undernutrition in Rural Ethiopia. In IFPRI Research Report. Washington, D.C., Rome and Addis Ababa: International Food Policy Research Institute and Istituto Nazionale della Nutrizione in collaboration with Ethiopian Health and Nutrition Research Institute.

Gilbert, Christopher L., Luc Christiaensen, and Jonathan Kaminski. 2015. Food Price Seasonality in Africa: Measurement and Extent. Unpublished manuscript.

Glewwe, Paul, Hanan. G. Jacoby, and Elizabeth. M. King. 2001. "Early childhood nutrition and academic achievement: A longitudinal analysis." Journal of Public Economics 81 (3):345-368.

Handa, Sudhanshu, and Gilead Mlay. 2006. "Food consumption patterns, seasonality and market access in Mozambique." Development Southern Africa 23 (4):541-560.

Headey, Derek. 2014. An Analysis of Trends and Determinants of Child Undernutrition in Ethiopia, 2000-2011. Ethiopia Strategy Support Program (ESSP) Working Paper 70.

Headey, Derek, John Hoddinott, Disha Ali, Roman Tesfaye, and Mekdim Dereje. 2015. "The other asian enigma: Explaining the rapid reduction of undernutrition in Bangladesh." World Development 66:749-761.

Herforth, Anna, Andrew Jones, and Per Pinstrup-Andersen. 2012. Prioritizing nutrition in agriculture and rural development: guiding principles for operational investments. HNP Discussion Paper 74152.

Hirvonen, Kalle, and John Hoddinott. 2014. Agricultural production and children's diets: Evidence from rural Ethiopia. IFPRI-ESSP Working Paper (69).

Hirvonen, Kalle, Alemayehu Seyoum Taffesse, and Ibrahim Worku. 2015. "Seasonality and household diets in Ethiopia." Public Health Nutrition forthcoming.

Hoddinott, John, Derek Headey, and Mekdim Dereje. 2015. "Cows, missing milk markets and nutrition in rural Ethiopia." Journal of Development Studies 51 (8):958-975.

Horton, Sue, and Richard H Steckel. 2013. "Malnutrition: global economic losses attributable to malnutrition 19002000 and projections to 2050." How Much Have Global Problems Cost the Earth? A Scorecard from 1900 to 2050:247-272.

Jacoby, Hanan G, and Bart Minten. 2009. "On measuring the benefits of lower transport costs." Journal of Development Economics 89 (1):28-38.

Jones, Andrew D, Scott B Ickes, Laura E Smith, Mduduzi NN Mbuya, Bernard Chasekwa, Rebecca A Heidkamp, Purnima Menon, Amanda A Zongrone, and Rebecca J Stoltzfus. 2014. "World Health Organization infant and young child feeding indicators and their associations with child anthropometry: a synthesis of recent findings." Maternal \& child nutrition 10 (1):1-17. 
Kaminski, Jonathan, Luc Christiaensen, and Christopher L Gilbert. 2014. The end of seasonality? New insights from Sub-Saharan Africa. World Bank Policy Research Working Paper (6907).

Khara, T, and C Dolan. 2014. "The relationship between wasting and stunting, policy, programming and research implications." Washington DC: USAID Technical Brief Paper.

Leonard, William R. 1991. "Household-level strategies for protecting children from seasonal food scarcity." Social Science \& Medicine 33 (10):1127-1133.

Leroy, Jef. 2011. "ZSCORE06: Stata module to calculate anthropometric z-scores using the 2006 WHO child growth standards." Statistical Software Components.

Maleta, K, SM Virtanen, M Espo, T Kulmala, and P Ashorn. 2003. "Seasonality of growth and the relationship between weight and height gain in children under three years of age in rural Malawi." Acta Paediatrica 92 (4):491-497.

Masset, Edoardo, Lawrence Haddad, Alexander Cornelius, and Jairo Isaza-Castro. 2012. "Effectiveness of agricultural interventions that aim to improve nutritional status of children: systematic review." $B M J 344$.

Mendez, Michelle A, and Linda S Adair. 1999. "Severity and timing of stunting in the first two years of life affect performance on cognitive tests in late childhood." The Journal of nutrition 129 (8):1555-1562.

Minten, Bart. 1999. "Infrastructure, market access, and agricultural prices: evidence from Madagascar." Report; International Food Policy Research Institute; Wahington, DC.

Panter-Brick, Catherine. 1997. "Seasonal growth patterns in rural Nepali children." Annals of human biology 24 (1):1-18.

Rienecker, Michele M, Max J Suarez, Ronald Gelaro, Ricardo Todling, Julio Bacmeister, Emily Liu, Michael G Bosilovich, Siegfried D Schubert, Lawrence Takacs, and Gi-Kong Kim. 2011. "MERRA: NASA's modernera retrospective analysis for research and applications." Journal of Climate 24 (14):3624-3648.

Ruel, Marie T, and Harold Alderman. 2013. "Nutrition-sensitive interventions and programmes: how can they help to accelerate progress in improving maternal and child nutrition?" The Lancet 382 (9891):536-551.

Stifel, David, and Bart Minten. 2015. Market Access, Welfare, and Nutrition: Evidence from Ethiopia. ESSP Working paper 77.

UNICEF. 1998. The state of the world's children 1998. New York: Oxford University Press.

Vaitla, Bapu, Stephen Devereux, and Samuel Hauenstein Swan. 2009. "Seasonal hunger: a neglected problem with proven solutions." PLOS Med 6(6).

Victora, C. G., M. de Onis, P. C. Hallal, M. Blossner, and R. Shrimpton. 2010. "Worldwide timing of growth faltering: revisiting implications for interventions." Pediatrics 125 (3):e473-80.

WHO. 2006. "WHO Child Growth Standards based on length/height, weight and age." Acta paediatrica Suppl 450:76-85. 


\section{Figures}

Figure 2.1: Map of the survey area in Hintalo Wajirat, Tigray

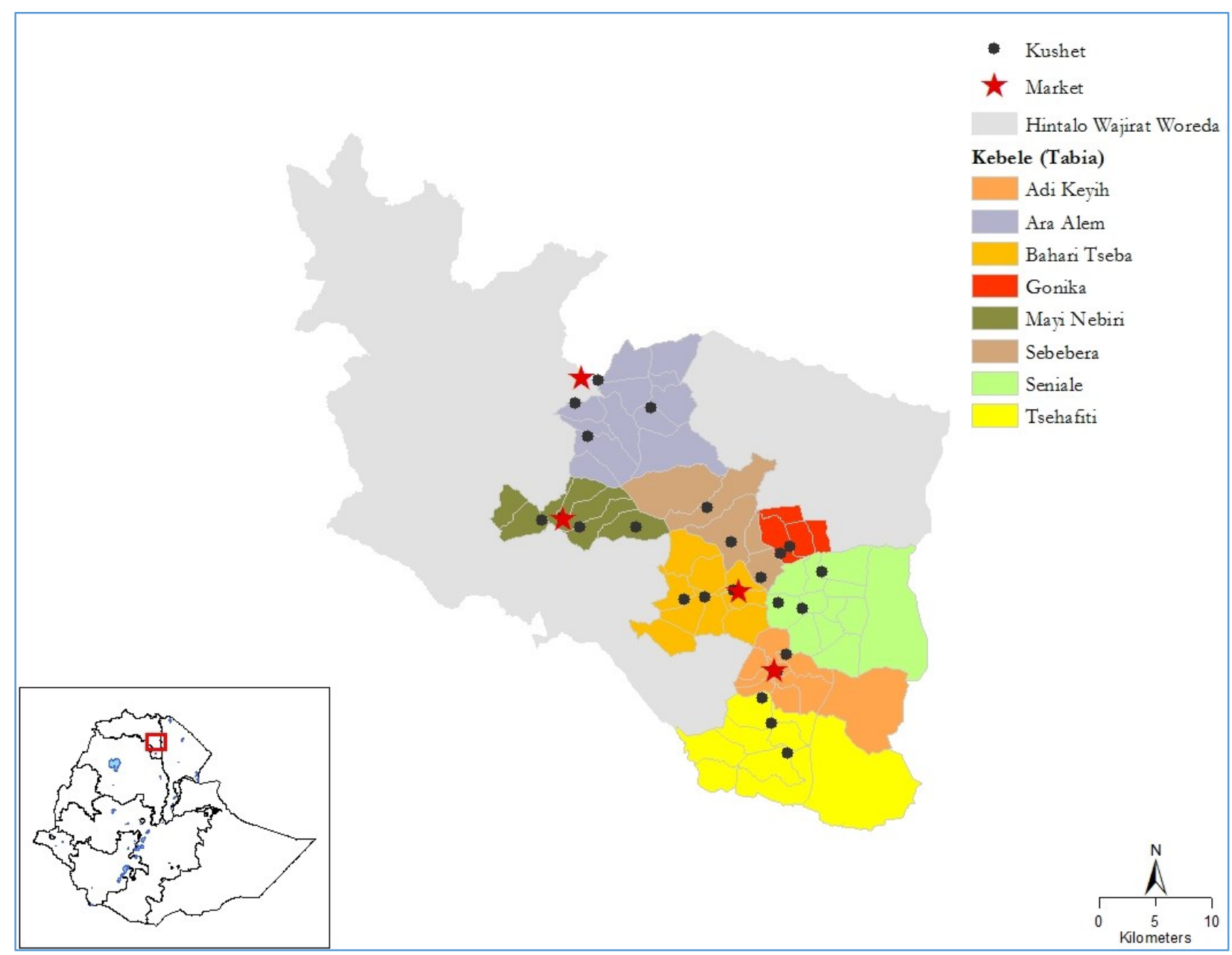

Note: The small map at the bottom-left corner shows the survey location in Ethiopia.

Source: UNICEF Tigray Social Cash Transfer Data 
Figure 2.2: Rainfall (in mm) by month in Hintalo Wajirat

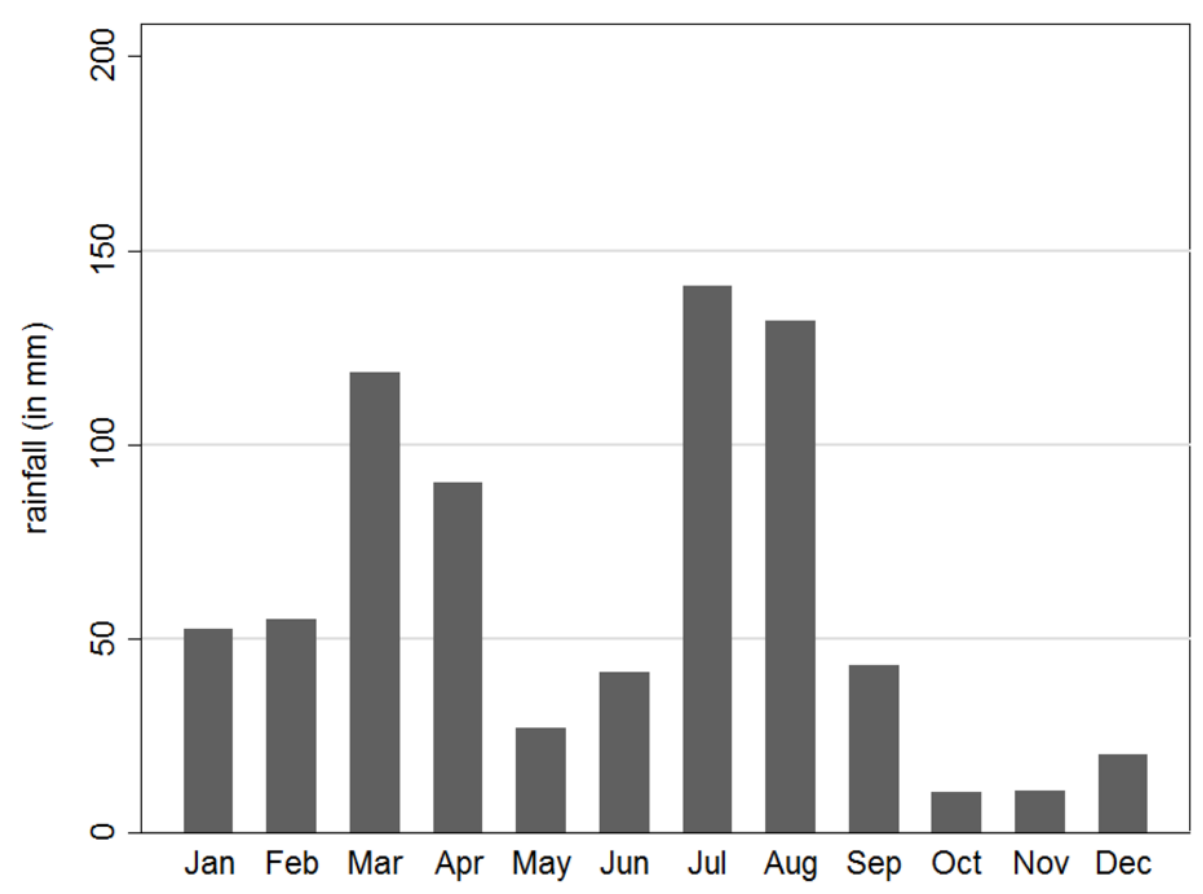

Note: Median rainfall in millimeters in 1981-2013 for each month.

Source: NASA-MERRA (Rienecker et al. 2011) 
Figure 2.3: Primary sources of food consumption by month

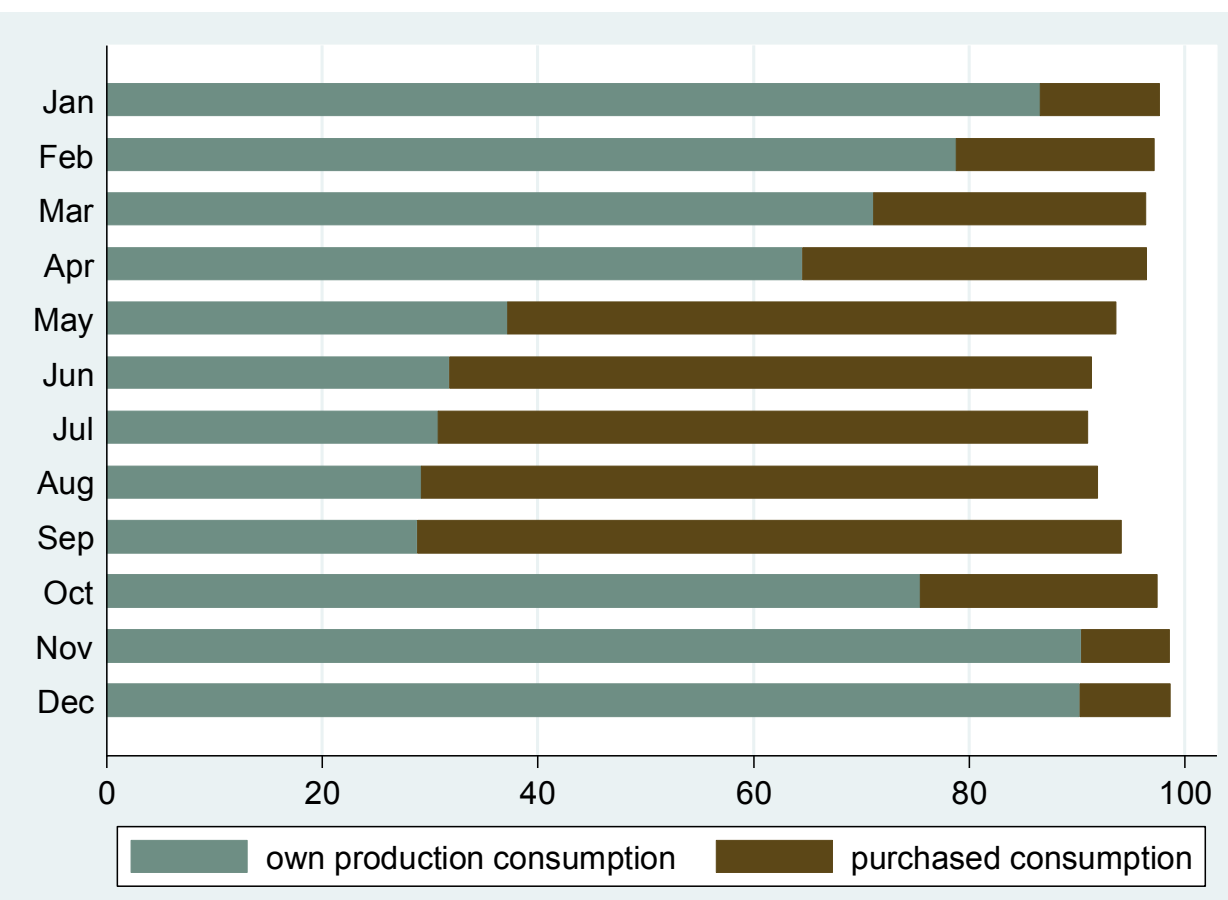

Note: omitted category are gifts and food aid.

Source: UNICEF Tigray Social Cash Transfer Data 
Figure 2.4: WHZ by age

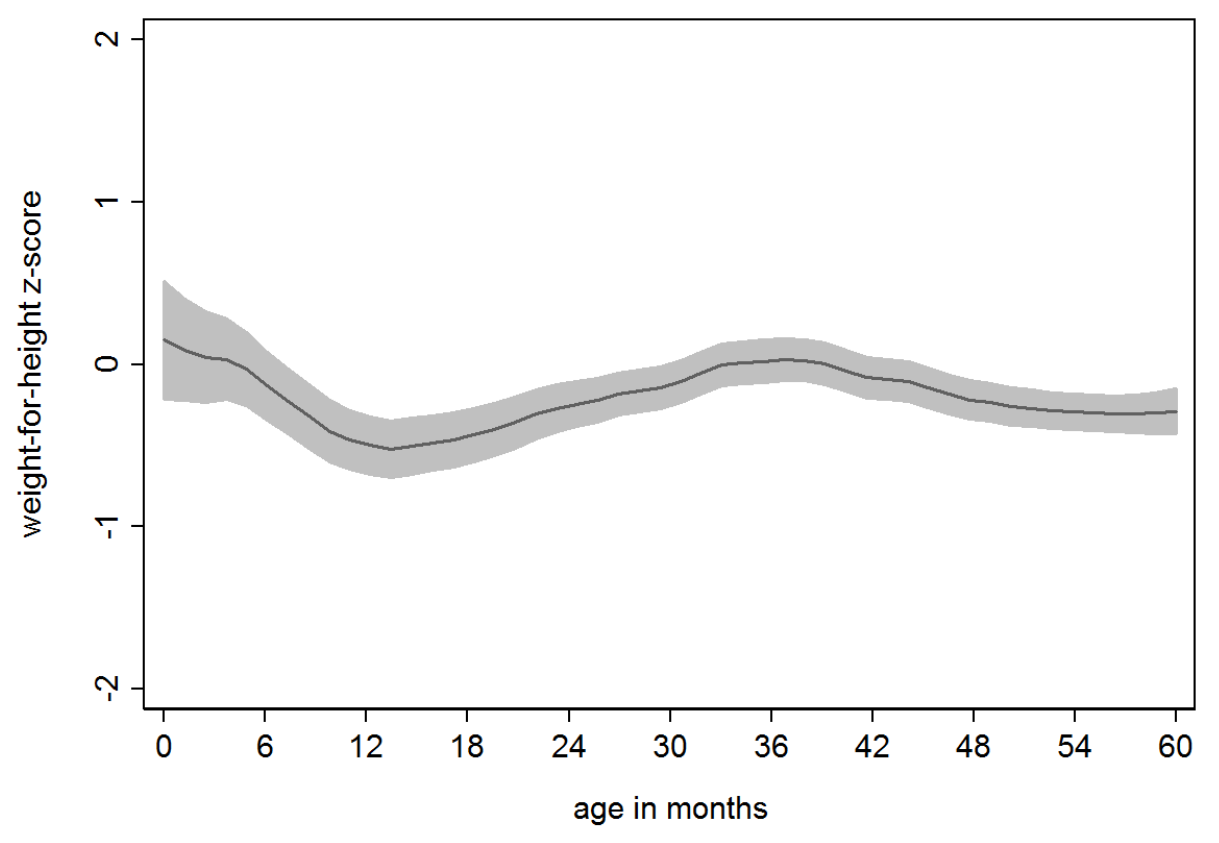

Note: Local polynomial regression.

Source: UNICEF Tigray Social Cash Transfer Data 
Figure 2.5: WAZ by age

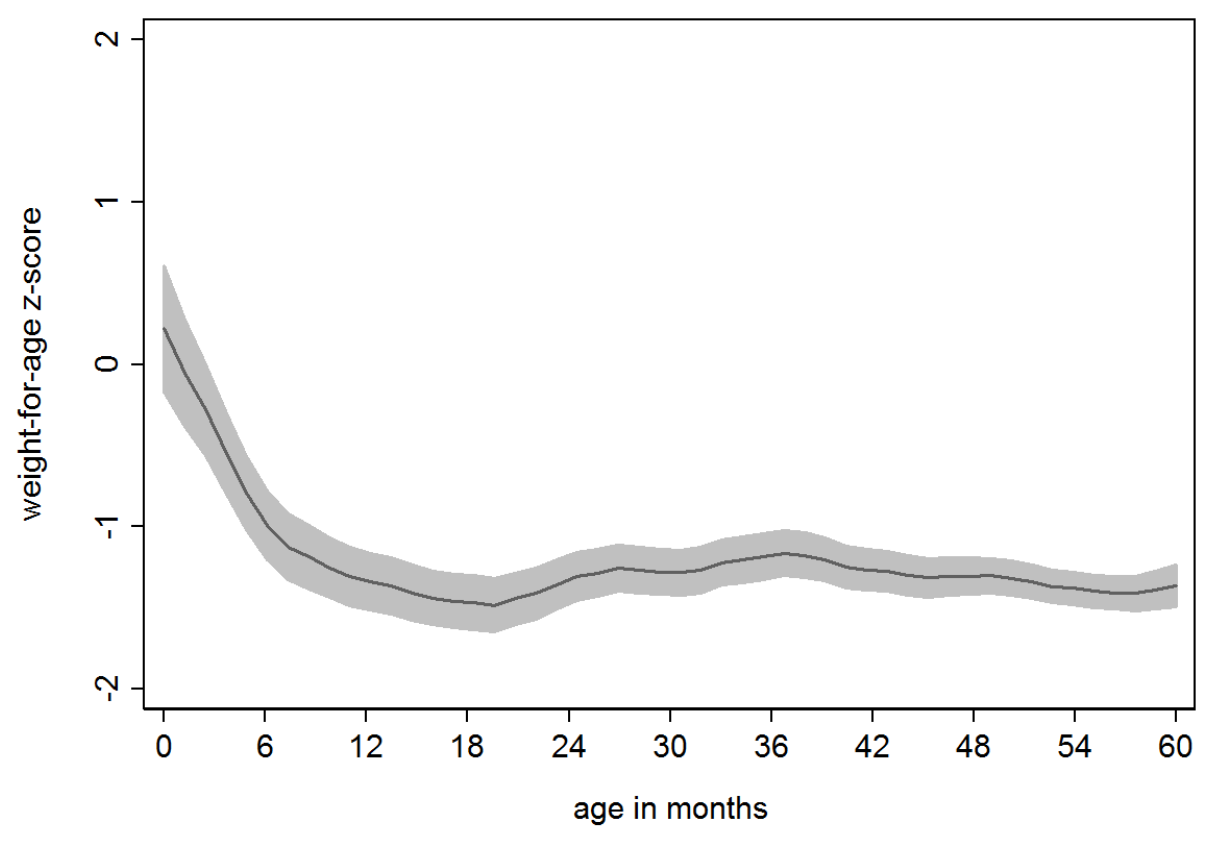

Note: Local polynomial regression.

Source: UNICEF Tigray Social Cash Transfer Data 


\section{Tables}

Table 2.1: Survey timing by round

\begin{tabular}{lll}
\hline Survey & Start Date & Finish Date \\
\hline Round 1* & 6 May 2012 & 26 June 2012 \\
Round 2 & 6 October 2012 & 27 October 2012 \\
Round 3 & 9 March 2013 & 29 March 2013 \\
Round 4* & 20 July 2013 & 11 August 2013 \\
Round 5 & 6 November 2013 & 26 November 2013 \\
Round 6 & 3 March 2014 & 25 March 2014 \\
Round 7* & 16 May 2014 & 17 July 2014 \\
\hline
\end{tabular}

* indicates a lean season period. 


\begin{tabular}{|c|c|c|c|}
\hline Variable description & $\begin{array}{c}\text { No of } \\
\text { observations }\end{array}$ & Mean & $\begin{array}{l}\text { Standard } \\
\text { Deviation }\end{array}$ \\
\hline \multicolumn{4}{|l|}{ Child anthropometric outcomes } \\
\hline Weight for age Z Score (WAZ) & 1,837 & -1.23 & 1.38 \\
\hline Underweight (WAZ<2) & 1,837 & 0.27 & 0.44 \\
\hline Weight for height Z Score (WHZ) & 1,656 & -0.21 & 1.38 \\
\hline Wasted (WHZ<2) & 1,656 & 0.08 & 0.28 \\
\hline Height for age $Z$ Score (HAZ) & 1,681 & -1.94 & 1.57 \\
\hline Stunted $(\mathrm{HAZ}<2)$ & 1,681 & 0.51 & 0.51 \\
\hline \multicolumn{4}{|l|}{ Child level characteristics } \\
\hline Age of child, in months & 1,858 & 33.88 & 16.81 \\
\hline$=1$ if male child & 1,858 & 0.50 & 0.50 \\
\hline \multicolumn{4}{|l|}{ Household level characteristics } \\
\hline Age of head of household (in years) & 1,858 & 49.34 & 16.67 \\
\hline$=1$ if head of household is male & 1,858 & 0.59 & 0.49 \\
\hline$=1$ if head is literate & 1,858 & 0.27 & 0.44 \\
\hline $\begin{array}{l}\text { Livestock ownership, principal component analysis } \\
\text { (PCA) }\end{array}$ & 1,858 & 0.75 & 2.18 \\
\hline Ownership of durable assets, PCA & 1,858 & -0.83 & 0.85 \\
\hline Ownership of productive equipment, PCA & 1,858 & 1.16 & 2.53 \\
\hline Number of males $0-5$ years & 1,858 & 0.72 & 0.72 \\
\hline Number of males $6-15$ years & 1,858 & 0.83 & 0.93 \\
\hline Number of males $16-60$ years & 1,858 & 0.90 & 0.92 \\
\hline Number of males $61+$ years & 1,858 & 0.20 & 0.40 \\
\hline Number of females $0-5$ years & 1,858 & 0.71 & 0.69 \\
\hline Number of females $6-15$ years & 1,858 & 0.78 & 0.94 \\
\hline Number of females $16-60$ years & 1,858 & 1.37 & 0.73 \\
\hline Number of females $61+$ years & 1,858 & 0.15 & 0.36 \\
\hline Euclidian distance to market (in $\mathrm{km}$ ) & 1,858 & 5.48 & 2.78 \\
\hline$=1$ if distance to market is less than $3.5 \mathrm{~km}$ & 1,858 & 0.24 & 0.42 \\
\hline \multicolumn{4}{|l|}{ Time variables } \\
\hline$=1$ if lean season & 1,858 & 0.62 & 0.48 \\
\hline$=1$ if lean season and close to market & 1,858 & 0.15 & 0.35 \\
\hline$=1$ if lean season and far from the market & 1,858 & 0.48 & 0.50 \\
\hline$=1$ if sufficient season and close to market & 1,858 & 0.09 & 0.29 \\
\hline$=1$ if sufficient season and far from the market & 1,858 & 0.29 & 0.45 \\
\hline
\end{tabular}

Source: UNICEF Tigray Social Cash Transfer Data 
Table 4.1: Impact of seasonality on child anthropometric outcomes

\begin{tabular}{lcccc}
\hline & $\mathbf{1}$ & $\mathbf{2}$ & $\mathbf{3}$ & $\mathbf{4}$ \\
\hline \multicolumn{1}{c}{ Dependent variable: } & $\mathbf{W H Z}$ & $\mathbf{W A Z}$ & $\mathbf{W H Z}$ & $\mathbf{W A Z}$ \\
\hline lean season & $-0.286^{* * *}$ & $-0.205^{* * *}$ & -0.166 & $-0.290^{* *}$ \\
& $(0.071)$ & $(0.067)$ & $(0.131)$ & $(0.123)$ \\
(log) distance to the market & $-0.075^{*}$ & $-0.123^{* * *}$ & -0.021 & $-0.160^{* * *}$ \\
& $(0.038)$ & $(0.037)$ & $(0.068)$ & $(0.060)$ \\
lean season X (log) distance to the market & $\mathrm{n} / \mathrm{a}$ & $\mathrm{n} / \mathrm{a}$ & -0.082 & 0.059 \\
& & & $(0.079)$ & $(0.072)$ \\
\hline linear time trend? & yes & yes & yes & yes \\
household level controls? & yes & yes & yes & yes \\
child level controls? & yes & yes & yes & yes \\
\hline Number of observations & 1656 & 1837 & 1656 & 1837 \\
$\mathrm{R}^{2}$ & 0.064 & 0.069 & 0.065 & 0.070 \\
\hline
\end{tabular}

Note: OLS model. Control variables are listed in Table 2.2. Standard errors clustered at the kushet level are in the parentheses. Statistical significance denoted at $* * * \mathrm{p}<0.01, * * \mathrm{p}<0.05,{ }^{*} \mathrm{p}<0.1$. Source: UNICEF Tigray Social Cash Transfer Data. 
Table 4.2: Impact of seasonality on child anthropometric outcomes - village fixed effects model

\begin{tabular}{lcccc}
\hline & $\mathbf{1}$ & $\mathbf{2}$ & $\mathbf{3}$ & $\mathbf{4}$ \\
\hline \multicolumn{1}{c}{ Dependent variable: } & $\mathbf{W H Z}$ & $\mathbf{W A Z}$ & $\mathbf{W H Z}$ & WAZ \\
\hline lean season & $-0.278^{* * *}$ & $-0.199^{* * *}$ & $-0.169^{* *}$ & $-0.275^{* * *}$ \\
& $(0.054)$ & $(0.046)$ & $(0.086)$ & $(0.049)$ \\
(log) distance to the market & $\mathrm{n} / \mathrm{a}$ & $\mathrm{n} / \mathrm{a}$ & $\mathrm{n} / \mathrm{a}$ & $\mathrm{n} / \mathrm{a}$ \\
& & & & \\
lean season X $(\log )$ distance to the market & $\mathrm{n} / \mathrm{a}$ & $\mathrm{n} / \mathrm{a}$ & $-0.075^{*}$ & 0.052 \\
& & & $(0.044)$ & $(0.034)$ \\
\hline linear time trend? & yes & yes & yes & yes \\
household level controls? & yes & yes & yes & yes \\
child level controls? & yes & yes & yes & yes \\
kushet fixed effects? & yes & yes & yes & yes \\
\hline $\begin{array}{l}\text { Number of observations } \\
\mathrm{R}^{2}\end{array}$ & 1656 & 1837 & 1656 & 1837 \\
\hline
\end{tabular}

Note: OLS model. Control variables are listed in Table 2.2. Standard errors clustered at the kushet level are in the parentheses. Statistical significance denoted at $* * * p<0.01, * * p<0.05, * p<0.1$.

Source: UNICEF Tigray Social Cash Transfer Data. 
Table 4.3: Impact of seasonality on child anthropometric outcomes by market access

\begin{tabular}{lcc}
\hline & $\mathbf{1}$ & $\mathbf{2}$ \\
\hline \multicolumn{1}{c}{ Dependent variable: } & WHZ & WAZ \\
\hline Sufficient season \& close to market $(\mathrm{A})$ & $0.383^{* * *}$ & $0.484^{* * *}$ \\
& $(0.117)$ & $(0.119)$ \\
Sufficient season \& far from the market $(\mathrm{B})$ & $0.312^{* * *}$ & $0.177^{* * *}$ \\
& $(0.069)$ & $(0.054)$ \\
Lean season \& close to market $(\mathrm{C})$ & $0.185^{* *}$ & $0.192^{* *}$ \\
& $(0.090)$ & $(0.093)$ \\
Lean season \& far from the market & reference & reference \\
\hline Linear time trend? & yes & yes \\
Household level controls? & yes & yes \\
Child level controls? & yes & yes \\
\hline F-test: $(A)-(B)=0$ & $\mathrm{p}=0.580$ & $\mathrm{p}=0.022$ \\
F-test: $(A)-(C)=0$ & $\mathrm{p}=0.005$ & $\mathrm{p}=0.000$ \\
F-test: $(B)-(C)=0$ & $\mathrm{p}=0.229$ & $\mathrm{p}=0.888$ \\
\hline Number of observations & 1656 & 1837 \\
$\mathrm{R}^{2}$ & 0.064 & 0.069 \\
\hline
\end{tabular}

Note: OLS model. Control variables are listed in Table 2.2. Standard errors clustered at the kushet level are in the parentheses. Statistical significance denoted at $* * * \mathrm{p}<0.01, * * \mathrm{p}<0.05, * \mathrm{p}<0.1$.

Source: UNICEF Tigray Social Cash Transfer Data 
Table 5.1: Impact of seasonality and market access on children's diets and diarrhea rates

\begin{tabular}{lcccc}
\hline & $\mathbf{1}$ & $\mathbf{2}$ & $\mathbf{3}$ & $\mathbf{4}$ \\
\hline \multicolumn{1}{c}{ Dependent variable: } & DDS & ASF & dairy & diarrhea \\
\hline Sufficient season \& close to market (A) & $0.710^{* * *}$ & $0.077^{* *}$ & $0.127^{* * *}$ & 0.030 \\
& $(0.197)$ & $(0.038)$ & $(0.032)$ & $(0.027)$ \\
Sufficient season \& far from the market (B) & $0.335^{* * *}$ & 0.019 & 0.010 & $0.028^{*}$ \\
& $(0.118)$ & $(0.024)$ & $(0.017)$ & $(0.014)$ \\
Lean season \& close to market $(\mathrm{C})$ & $0.729 * * *$ & 0.014 & -0.006 & 0.003 \\
& $(0.165)$ & $(0.031)$ & $(0.021)$ & $(0.022)$ \\
Lean season \& far from the market & reference & reference & reference & reference \\
\hline Linear time trend? & yes & yes & yes & yes \\
Household level controls? & yes & yes & yes & yes \\
Child level controls? & no & no & no & yes \\
\hline F-test: $(A)-(B)=0$ & $\mathrm{p}=0.069$ & $\mathrm{p}=0.150$ & $\mathrm{p}=0.000$ & $\mathrm{p}=0.926$ \\
F-test: $(A)-(C)=0$ & $\mathrm{p}=0.935$ & $\mathrm{p}=0.158$ & $\mathrm{p}=0.000$ & $\mathrm{p}=0.311$ \\
F-test: $(B)-(C)=0$ & $\mathrm{p}=0.025$ & $\mathrm{p}=0.888$ & $\mathrm{p}=0.509$ & $\mathrm{p}=0.296$ \\
\hline Number of observations & 1852 & 1852 & 1852 & 1705 \\
$\mathrm{R}^{2}$ & 0.207 & 0.041 & 0.078 & 0.052 \\
\hline
\end{tabular}

Note: Column 1 is OLS and columns 2 to 4 are estimated using linear probability model. Control variables are listed in Table 2.2. Standard errors clustered at the kushet level are in the parentheses. Statistical significance denoted at $* * * \mathrm{p}<0.01, * * \mathrm{p}<0.05, * \mathrm{p}<0.1$.

Source: UNICEF Tigray Social Cash Transfer Data 